\title{
Comparison of burnout, vigor and education satisfaction of music and art majors in department of fine arts education
}

\author{
Rasim Erol Demirbatır \\ Department of Fine Arts Education, Bursa Uludağ University, Turkey
}

\begin{tabular}{l} 
Article Info \\
\hline Article history: \\
Received Feb 21, 2020 \\
Revised May 6, 2020 \\
Accepted Jul 20, 2020 \\
\hline Keywords: \\
Art education \\
Burnout \\
Educational satisfaction \\
Music education \\
Vigor
\end{tabular}

\section{Corresponding Author:}

Rasim Erol Demirbatır,

Department of Fine Arts Education,

Bursa Uludağ University,

Özlüce Görükle Kampüsü, 16059 Nilüfer/Bursa, Turkey.

Email: redemir@uludag.edu.tr

\begin{abstract}
The success of an educational institution is largely based on student motivation and educational satisfaction and their happiness at their place of education. It is therefore very important to maintain high quality in education to determine the case of students' well-being in order to improve the standards of study. In this regard, the aim of this study was to identify the status of students in terms of their level of burnout, vigor and educational satisfaction at the Department of Fine Arts Education. There were 250 students participated in the study. To determine the level of burnout and vigor, Shirom-Melamed Burnout and Vigor Measures were employed, and to measure the educational satisfaction levels, educational satisfaction questionnaire was used. The results show that music majors have lower vigor than art majors. Gender does not have significant effect on any of the scores. Burnout, vigor and educational satisfaction differ according to the year of education for music major, but only vigor differs for art majors. Mother's education level has significant effect on burnout and vigor for music majors and on education satisfaction for art majors. GPA is not correlated with none of burnout, vigor or educational satisfaction.
\end{abstract}

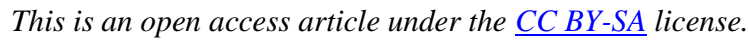

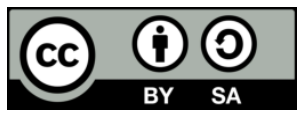

\section{INTRODUCTION}

The success of an educational institution is largely based on student motivation, educational satisfaction and their happiness at their place of education. It is therefore very important to maintain high quality in education to determine the case of students' education satisfaction in order to improve the standards of education. In this regard, the aim of this study was to identify the status of students in terms of their level of burnout, vigor and educational satisfaction of music and art majors in Department of Fine Arts Education.

There are psychological difficulties that university education brings to the student due to reasons such as moving to a new city, living separately from the family, increasing responsibilities regarding their own decisions. Whether the department that he/she enrolled is among the student's first choices can be estimated to affect his/her satisfaction in education life. In addition, it may be thought that the reasons such as encountering a different environment than the student expected, making the program harder than expected or not suitable for him /her may be effective in the burnout, vigor and education satisfaction of the student. Moreover, the student may have to cope with some specific problems related to the field of study For example, there are studies stating that more than half of the music students may encounter health-related problems arising from their profession [1-6]. 
On the other hand, there is extensive literature revealing that music practice can contribute to a better life with more psychological well-being and happiness [7-11]. Learning and making music can benefit the health of amateur musicians, both physically [12] and psychologically [13]. Nevertheless, the physical and psychological demands placed on those involved in music professionally can have a negative impact on their well-being [14]. The adverse effects of musical activity are likely to be most pronounced for musicians, since preparing and performing involves a substantial amount of intellectual and physical effort. In effect, their health status is likely to have consequences for their ability to make music [15]. Indeed, music history has seen excellent artists who had withdrawn from music due to mental problems such as Vladimir Horowitz, for example, is believed to have stopped his career due to depression $[15,16]$. Despite the growing body of research on various aspects of the psychological health of performers, the published literature on their music-related ill-being is largely limited to that on performance anxiety. Similarly, there is limited research on the well-being of performers' experience specifically related to music. General literature appears to identify burnout and commitment as indices of employee ill-being and well-being in relation to work $[17,18]$ and student ill-being in relation to research, there is a significant lack of research in the population of musical performers to address these issues.

Nevertheless, according to anecdotal evidence, even the most experienced performers can be burned-out: the pianist Van Cliburn is known to have been a victim of burnout, to such a degree that he has withdrawn from his career as a performer for several years. In fact, there are anecdotal findings in music education literature that burnout affects music students [19]. Nevertheless, it is important to note that the absence of psychological ill-being does not necessarily mean well-being [20], in other words an "optimal psychological awareness and functioning" [21]. This means that both the negative and positive states (i.e. both burnout and engagement) that performers may encounter with respect to music need to be investigated if their healthy participation is to be better understood. While burnout and engagement reflect well-being specifically related to music, they are likely to influence the physical health and overall functioning of performers, which underlines the importance of researching their effect on performance students.

Next, it is necessary to determine the degree to which performance students feel burned-out and/or engaged. Therefore, in order to promote wellbeing and avoid ill-health, it is of primary importance to find out what underpins the production of burnout and commitment and to shed some light on how it relates to the well-being and functioning of students. In order to target students at particular risk, it is important to identify factors related to sub-optimal music-related well-being that are both modifiable, at least to some degree, such as personal factors and the immediate learning environment, and those beyond the direct control of students. Exploring how different music education systems affect performance-related ill-being and wellbeing is also worthwhile in order to identify the factors that are most likely to compromise students' musicrelated well-being or, conversely, to promote their positive attitudes towards music-making.

Educational satisfaction is the most common issue in today's modern world. People working in almost all occupations work longer and longer, which decreases educational satisfaction and raises their burnout rates. Educational satisfaction can be characterized as a body of feelings that a person has towards internal and external factors related to his or her interests [22]. In addition, high burnout rates are associated with poor educational satisfaction [23-27] and educational burnout is also normal as a result of intense relationships and challenging places of study [28]. Burnout was first identified by Freudenberger in 1974 [29] as being physically and emotionally exhausted due to educational conditions. Sadly, students have a high level of fatigue relative to other careers [30, 31].

In every educational forum, the degree of burnout and satisfaction affects the quality of education, the amount of contributions made in the field of science and the creation of inventions in their own sector. In other words, it is only when academic staff are comfortable with their working conditions that students can become innovative, successful and ready to create new ideas for their career. Karabiyik, Eker and Anbar [32] reported that the study of the environment, the promotion and assessment, and the research fund have an effect on burnout among students. Burnout is considered to be a serious issue that could cause many students to quit. Maslach, Schaufeli and Leiter [33] split the burnout into three dimensions: fatigue, frustration and inefficiency. Burnout was initially established in professions involving human contact [34]. This is probably due to the strength of interpersonal relationships in which students study too much. It is recognized that the style of management of abuse, frequently encountered by professionals such as health workers and students, is harmful to personal health, morality and success [35].

Sadly, the literature on burnout and vigor of academicians at the Fine Arts Education Departments is not enough to obtain sufficient information to determine the level of burnout and vigor of students. This current study therefore seeks to determine the level of burnout, vigor and education satisfaction of students studying music and arts. It is possible that burnout, vigor and education satisfaction of music education students will be different from other students due to the mentioned characteristics of music education. In Turkey teacher training instutions are organized so that both music majors and art majors are constructed 
in the same department in the name of the department of fine arts education. Although there are no studies in the literature investigating the burnout, vigor and educational satisfaction of art majors it is thought that the music majors will differ from those of art majors due to the mentioned features even if they are under the same department. From this perspective, the question of whether the effect of independent variables of gender, education year, parents' education level and health status on the dependent variables of burnout, vigor and education satisfaction varies according to the major of student is considered worthy of researching.

As mentioned above, although there are studies addressing the health problems of the music students or the studies that the music practice brings psychological well-being and happiness, there is no study in the literature investigating whether music students differ from other students in terms of burnout, vigor and educational satisfaction. And since both music majors and art majors are constructed in the same department in Turkey, comparing music and art majors will reveal whether music students have a special situation that affects their burnout, vigor or educational satisfaction levels. In this context, it is determined as a problem of the research whether music and art majors are different in terms of burnout vigor and educational satisfaction levels. In addition, it has been investigated whether the factors thought to be related to burnout vigor and educational satisfaction have different effects on these majors.

\section{RESEARCH METHOD}

Correlational research design is employed in the study. Music and art majors' burnout, vigor and educational satisfaction levels were analyzed in terms of gender, education year, parents' education level, and health status. The correlations between burnout, vigor, educational satisfaction and health status were also analyzed.

\subsection{Sampling}

Totally 250 students of music and art majors in Department of Fine Arts Education participated voluntarily to the study. Detailed information of participants is given in Table 1.

Table 1. Demographic characteristics of the participants

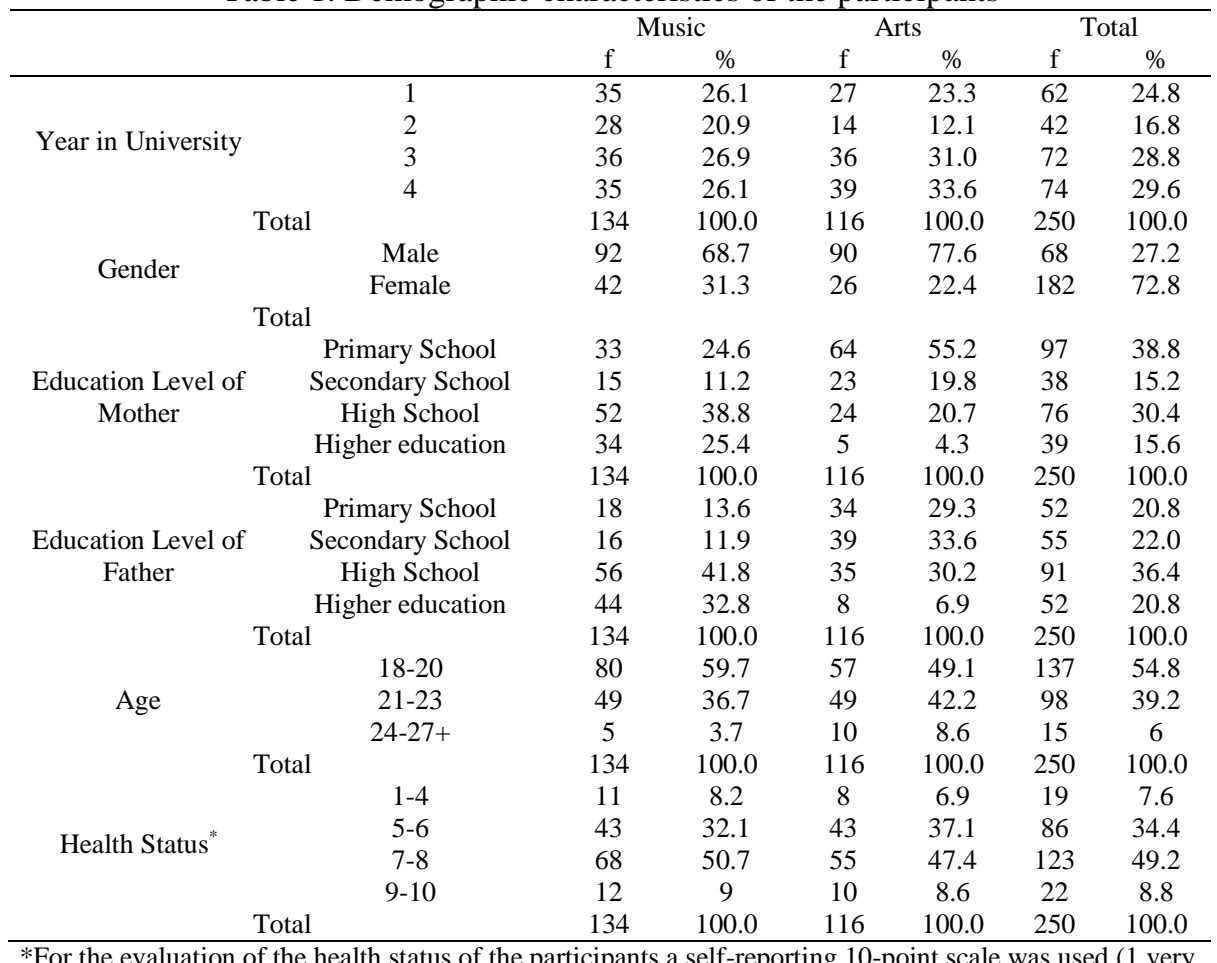

bad to 10 excellent)

\subsection{Data collection tools}

Students' burnout levels were measured via Turkish version of [36] Shirom-Melamed Burnout Measure (SMBM) [37]. SMBM has three subscales. The three subscales are the physical fatigue (PF) factor 
(6 items), the cognitive weariness (CW) factor (5 items), and the emotional exhaustion (EEx) factor (3 items). SMBM is a 7-point Likert-type scale. Turkish version [36] of Shirom-Melamed Vigor Measure (SMVM) [37] was employed to determine the vigor levels. Its 3 factors are physical strength (PHY, 5 items); emotional energy (EE, 4 items); and cognitive liveliness (CL, 3 items). All 14 items were measured on a 7-point Likert-type scale.

Educational Satisfaction (ES), which refers to a student's subjective, cognitive evaluation of school life using her or his own standards related to several specific school life domains [38] were measured by ES questionnaire developed by Demirbatir [38] which has 20 items of 5-point Likert-type scale, where $1=$ strongly disagree, and $5=$ strongly agree. Participants were also asked to indicate their health condition using a 10 -point scale, from 1 = very unhealthy to 10 = very healthy.

For SMBM, the Cronbach's $\alpha$ for total scale is 0.88 ; for PF factor it is 0.92 ; for $\mathrm{CW}$ factor it is 0.88 and for EEx factor it is 0.79 , meaning the SMBM and its three items provide good level of internal consistency and an accurate measure of the variable, burnout. For SMVM, the Cronbach $\alpha$ for total scale is 0.84; for PHY factor it is 0.87 ; for EE factor it is 0.85 and for CL factor it is 0.91 . For ES, the Cronbach $\alpha$ calculated to assess the internal consistency of ES is 0.89 . The Cronbach $\alpha$ value stated for SMVM and ES indicates that these surveys provide good level of internal consistency and an accurate measure of the variable.

\subsection{Data analysis}

In the study, the Cronbach's $\alpha$ was used to measure the internal consistency between the items and to determine whether the survey is accurately measuring the variable of interest. When comparing the scale scores of art and music majors; and the scale socres of female and male students independent t-tests were employed. One-way ANOVA with Bonferroni post-hoc comparisons was used to test significant differences between and within groups, considering year of education and Kruskal Wallis H test for mother and father's level of education. In addition, correlation coefficients were calculated between scales (SMBM, SMVM, ES) and GPA and health were performed. Since the Health scores were in ordinal scale, Spearman's rho was reported for correlations including Health scores. For other comparisons Pearson correlation coefficient was used.

\section{RESULTS AND DISCUSSION}

Table 2 shows the comparisons of SMBM, SMVM, and ES scores according to Majors of Music and Art. As seen in the Table 2, music majors' SMBM scores were not significantly different than Art majors, $\mathrm{p}>0.05$, even though the mean values for all three items of SMBM (PF,CW,EEx) were higher for music majors comparing to arts majors. For SMVM and its subdimension PHY, music majors were significantly lower than Art majors, $\mathrm{p}<0.05$. This means that music students feel less vigorous and less physical strength comparing to the arts students. ES scores were not significantly different, $p>0.05$, indicating that both arts and music students feel similar levels of educational satisfaction.

In the literature there are studies showing that music practice can contribute to a better life with more psychological well-being and happiness [7-11]. But for students in music programs, studies indicates the opposite results. Researchers such as Spahn, Strukely \& Lehman [39] found that music students' depression and anxiety scores were higher than those of the medical and sports students.

Table 2. Comparisons of SMBM, SMVM, and ES scores according to majors

\begin{tabular}{cccccccc}
\hline Scale & Major & $\mathrm{N}$ & $\mathrm{M}$ & $\mathrm{SD}$ & $\mathrm{t}$ & $\mathrm{df}$ & $\mathrm{p}$ \\
\hline SMBM & Music & 134 & 3.73 & 1.04 & 1.757 & 248 & 0.08 \\
& Art & 116 & 3.50 & 0.99 & & & \\
PF & Music & 134 & 4.71 & 1.38 & 1.503 & 248 & 0.13 \\
& Art & 116 & 4.45 & 1.29 & & & \\
CW & Music & 134 & 3.34 & 1.46 & 0.982 & 248 & 0.33 \\
& Art & 116 & 3.17 & 1.32 & & & \\
EEx & Music & 134 & 2.42 & 1.35 & 1.576 & 248 & 0.12 \\
& Art & 116 & 2.16 & 1.26 & & & \\
SMVM & Music & 134 & 4.59 & 0.89 & -2.147 & 248 & 0.03 \\
& Art & 116 & 4.84 & 0.95 & & & \\
PHY & Music & 134 & 3.91 & 1.26 & -2.630 & 248 & 0.01 \\
& Art & 116 & 4.30 & 1.05 & & & \\
CL & Music & 134 & 4.82 & 1.37 & -1.654 & 248 & 0.1 \\
& Art & 116 & 5.10 & 1.32 & & & \\
EE & Music & 134 & 5.26 & 1.31 & -0.318 & 248 & 0.75 \\
& Art & 116 & 5.31 & 1.46 & & & \\
ES & Music & 134 & 3.43 & 0.64 & 1.393 & 248 & 0.17 \\
& Art & 116 & 3.32 & 0.60 & & & \\
\hline
\end{tabular}


Table 3 shows that for both music and art students, gender did not have any significant effect on SMBM, SMVM and ES scores, $\mathrm{p}>0.05$. In the literature, there are some studies that show females have more burnout and less vigor, and in some studies there is no significant difference [35]. In this study, female and male students seemed to have similar levels of burnout, vigor and educational satisfaction. As seen in Table 4, ANOVA results showed that SMBM scores significantly varied $(p<0.01)$ according to the Year for music majors. Post hoc tests showed that 4th year music majors have significantly higher SMBM scores than 1st year music majors. This indicates that 4th year students feel more burned-out than 1st year students, which could be due to increased workload, stress and difficulty of the course. But for Art majors, year of education did not significantly affect the SMBM scores.

Table 3. Comparisons of SMBM, SMVM, ES scores according to gender

\begin{tabular}{clcccccc}
\hline & \multicolumn{3}{c}{ Music } & \multicolumn{3}{c}{ Art } \\
& Gender & $\mathrm{M}(\mathrm{SD})$ & $\mathrm{t}$ & $\mathrm{p}$ & $\mathrm{M}(\mathrm{SD})$ & $\mathrm{t}$ & $\mathrm{p}$ \\
\hline \multirow{2}{*}{ SMBM } & Female & $3.77 \pm 1.07$ & 0.625 & 0.53 & $3.51 \pm 0.92$ & 0.148 & 0.88 \\
& Male & $3.65 \pm 0.99$ & & & $3.48 \pm 1.20$ & & \\
\multirow{2}{*}{ SMVM } & Female & $4.56 \pm 0.90$ & -0.49 & 0.63 & $4.91 \pm 0.82$ & 1.433 & 0.15 \\
& Male & $4.64 \pm 0.90$ & & & $4.60 \pm 1.32$ & & \\
\multirow{2}{*}{$\mathrm{ES}$} & Female & $3.45 \pm 0.59$ & 0.639 & 0.52 & $3.36 \pm 0.59$ & 1.281 & 0.20 \\
& Male & $3.38 \pm 0.73$ & & & $3.19 \pm 0.65$ & & \\
\hline
\end{tabular}

Table 4. Comparisons of SMBM, SMVM, ES scores according to the year of education

\begin{tabular}{cccccccccc}
\hline & \multicolumn{3}{c}{ Music } & \multicolumn{5}{c}{ Art } \\
& Year & $\mathrm{M}(\mathrm{SD})$ & $\mathrm{F}$ & $\mathrm{p}$ & Diff. & $\mathrm{M}(\mathrm{SD})$ & $\mathrm{F}$ & $\mathrm{p}$ & Diff. \\
\hline \multirow{4}{*}{ SMBM } & $1^{\text {st }}$ & $3.33 \pm 1.04$ & 3.78 & 0.01 & $1<4$ & $3.88 \pm 1.03$ & 2.03 & 0.11 & \\
& $2^{\text {nd }}$ & $3.64 \pm 0.95$ & & & & $3.56 \pm 1.07$ & & & \\
& $3^{\text {rd }}$ & $3.79 \pm 0.94$ & & & & $3.29 \pm 0.70$ & & & \\
& $4^{\text {th }}$ & $4.13 \pm 1.10$ & & & & $3.42 \pm 1.10$ & & & \\
& $1^{\text {st }}$ & $4.91 \pm 0.84$ & 4.38 & 0.01 & $4<1$ & $4.36 \pm 1.05$ & 4.15 & 0.01 & $1<3$, \\
& $2^{\text {nd }}$ & $4.69 \pm 0.86$ & & & & $4.62 \pm 0.95$ & & & $1<4$, \\
& $3^{\text {rd }}$ & $4.59 \pm 0.90$ & & & & $5.00 \pm 0.71$ & & & $2<4$ \\
& $4^{\text {th }}$ & $4.18 \pm 0.85$ & & & & $5.09 \pm 0.97$ & & & \\
& $1^{\text {st }}$ & $3.92 \pm 0.48$ & 15.55 & 0.01 & $4<3$, & $3.41 \pm 0.52$ & 1.01 & 0.39 & \\
ES & $2^{\text {nd }}$ & $3.37 \pm 0.60$ & & & $4<1$, & $3.44 \pm 0.49$ & & & \\
& $3^{\text {rd }}$ & $3.39 \pm 0.54$ & & & $3<1$, & $3.35 \pm 0.53$ & & & \\
& $4^{\text {th }}$ & $3.03 \pm 0.59$ & & & $2<1$ & $3.19 \pm 0.74$ & & & \\
\hline
\end{tabular}

SMVM scores significantly varied according to the Year for music majors. Post hoc tests showed that 1st year music majors have significantly higher SMVM scores than 4th year music majors, implying that 1 st year music students are more vigorous comparing to 4th year students. The year had also significant affect on Art majors' SMVM scores, showing a gradual increase in SMVM scores from 1st year to 4th year. Post hoc tests showed that 1 st year art majors had significantly lower scores $(\mathrm{p}<0.01)$ than $3 \mathrm{rd}$ and 4 th year art majors. And 2nd year art majors had also lower scores than 4th year art majors. These results suggest that arts students have an increased vigor as they progress through their degree.

ES scores significantly varied according to the year for music majors. Post hoc tests showed that $1 \mathrm{st}$ year music majors have significantly higher ES scores than 2nd, 3rd, and 4th year music majors, indicating a higher level of educational satisfaction on the first year. There is a significant decrease of ES scores when students move to 2 nd year and maintain a similar average score in 3rd year. In addition, 3rd year music majors were higher than 4th years, revealing that educational satisfaction significantly drops on the 4th year comparing to the previous years of education. However for art majors, year did not significantly affect the ES scores, showing that students maintained a similar level of educational satisfaction throughout their years of arts education. These results showed that as the music students progressed through years of music education, they felt more burned-out, less vigorous and educational satisfaction decreased, also indicating an increase in negative emotions. Similar results were obtained from previous Turkish studies [40, 41].

As seen in the Table 5, music students whose mothers' education level was high school had significantly lower SMBM scores than students whose mothers' education level was higher education, $\mathrm{p}<0.05$, indicating that students whose mothers' education level was higher education feel more burned-out. Music students whose mothers' education level was high school had higher SMVM an ES scores than students whose mothers' education level was higher education, $\mathrm{p}<0.05$ indicating that students whose mothers' education level was high school feel more vigorous and satisfied comparing to the other groups. Art students whose mothers' education level was high school had significantly lower ES scores than students 
whose mothers' education level was primary school, $p<0.05$, and overall they have the lowest average score indicating that these students, whose mothers' education level was high school, are less satisfied with their arts education. Table 6. shows the effect of father's education on scores. As seen in the Table 6, father's education level did not have any significant effect on both music and art students' SMBM, SMVM or ES scores, $\mathrm{p}>0.05$.

Table 5. Comparisons of SMBM, SMVM, ES scores according to the mother's education level

\begin{tabular}{cccccccccc}
\hline & \multicolumn{3}{c}{ Music } & \multicolumn{5}{c}{ Art } \\
& Education & $\mathrm{M}(\mathrm{SD})$ & $\mathrm{H}$ & $\mathrm{p}$ & Diff. & $\mathrm{M}(\mathrm{SD})$ & $\mathrm{H}$ & $\mathrm{p}$ & Diff. \\
\hline \multirow{4}{*}{ SMBM } & 1 & $3.56 \pm 0.73$ & 9.906 & 0.02 & $4<5$ & $3.46 \pm 1.07$ & 5.642 & 0.13 & \\
& 2 & $3.97 \pm 1.58$ & & & & $3.63 \pm 0.83$ & & & \\
& 3 & $3.47 \pm 0.99$ & & & & $3.65 \pm 0.82$ & & & \\
& 4 & $4.19 \pm 0.95$ & & & & $2.67 \pm 1.09$ & & & \\
SMVM & 1 & $4.57 \pm 0.74$ & 11.034 & 0.01 & $5<4$ & $4.84 \pm 1.03$ & 4.940 & 0.17 & \\
& 3 & $4.77 \pm 0.95$ & & & & $4.96 \pm 0.66$ & & & \\
& 4 & $4.80 \pm 0.96$ & & & & $4.59 \pm 0.97$ & & & \\
& 1 & $4.19 \pm 0.80$ & & & & $5.43 \pm 0.83$ & & & \\
ES & $2.42 \pm 0.56$ & 8.827 & 0.03 & $5<4$ & $3.44 \pm 0.55$ & 8.461 & 0.04 & $4<2$ \\
& 3 & $3.28 \pm 0.65$ & & & & $3.36 \pm 0.60$ & & & \\
& 4 & $3.63 \pm 0.61$ & & & & $2.98 \pm 0.69$ & & & \\
\hline
\end{tabular}

1 = Primary School, 2 = Secondary School, $3=$ High School, 4 = Higher education .

Table 6. Comparisons of SMBM, SMVM, ES scores according to the father's education level

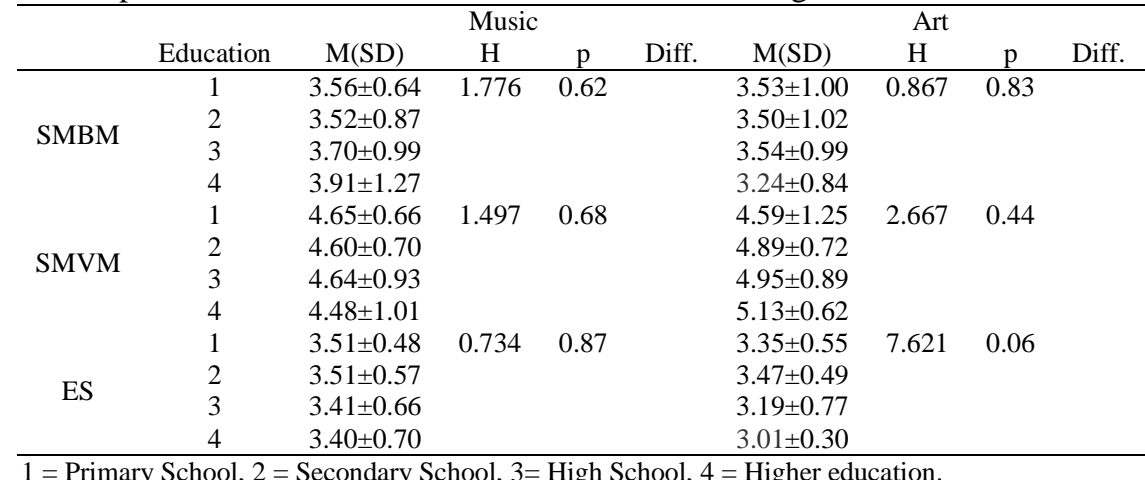

Table 7 shows the correlations between scale scores and GPA. The table shows that GPA of music students was not correlated to SMBM, SMVM, ES or Health. GPA of art students was not correlated with SMBM, SMVM and ES, however it was negatively correlated to Health score $(\mathrm{p}<0.05)$. This means that as the GPA scores increase, the health of arts students decrease. SMBM-SMVM scores, and SMBM-ES scores were negatively correlated $(\mathrm{p}<0.01)$ for both Music and Art majors. This means that as the level of burnout increase, the level of vigor and educational satisfaction decrease. In the literature, studies indicated that burnout has negative effect on vigor [35, 42]. This recent study's findings are parallel with the literature.

For music students, SMBM-Health scores were negatively correlated $(\mathrm{p}<0.01)$, indicating that as the level of burnout of students increase, their health levels decrease. The SMVM-ES and SMVM-Health were positively correlated $(\mathrm{p}<0.01)$, which is intuitive as their levels of vigor increase, their health and educational satisfaction levels increase. The ES-Health scores of music students were positively correlated $(\mathrm{p}<0.05)$, showing that as the health levels increase, the educational satisfaction increase. The SMBMHealth, SMVM-ES, SMVM-Health, and ES- Health scores of art students have no correlation. The results show that it's more important for music majors how healthy they feel since the health scores have a bigger effect on SMBM, SMVM and ES scores. 
Table 7. Correlations between scales and GPA

\begin{tabular}{ccccc}
\hline & \multicolumn{2}{c}{ Music } & \multicolumn{2}{c}{ Art } \\
& $\mathrm{r}^{*}$ & $\mathrm{p}$ & $\mathrm{r}^{*}$ & $\mathrm{p}$ \\
\hline GPA - SMBM & 0.05 & 0.66 & 0.04 & 0.69 \\
GPA - SMVM & -0.09 & 0.36 & -0.05 & 0.62 \\
GPA - ES & 0.09 & 0.37 & 0.12 & 0.26 \\
GPA - Health & 0.14 & 0.17 & -0.23 & 0.03 \\
SMBM - SMVM & -0.66 & $<0.01$ & -0.31 & $<0.01$ \\
SMBM - ES & -0.41 & $<0.01$ & -0.24 & $<0.01$ \\
SMBM - Health & -0.42 & $<0.01$ & -0.08 & 0.39 \\
SMVM - ES & 0.43 & $<0.01$ & 0.13 & 0.16 \\
SMVM - Health & 0.38 & $<0.01$ & 0.14 & 0.14 \\
ES - Health & 0.18 & 0.04 & 0.03 & 0.71 \\
\hline *Since the Health scores were in ordinal scale, Spearman's rho was
\end{tabular}

reported for correlations including Health scores.

\section{CONCLUSION}

This study aimed to compare the level of burnout, vigor and education satisfaction of music and art majors. The results showed that music majors had lower vigor than art majors. For both music and art majors gender did not have significant effect on any of the scales. Burnout, vigor and educational satisfaction differ according to the year of education for music majors, but only vigor differs for art majors. Mother's education level has significant effect on burnout, and vigor for music majors, whereas it has an effect on education satisfaction for art majors. Father's education level did not have any significant effect for both music and art majors. Results also showed that GPA was not correlated with none of burnout, vigor or educational satisfaction.

When only class loads and possible social stresses are considered music majors are not expected to have different burnout, vigor or education satisfaction levels than art majors. Considering that music majors have to spend hours to practice, it can be said that these students can spend less time on activities for relaxation, entertainment and sports. Since music is a performance-based art, it can be thought that music majors will experience more performance anxiety than art majors. This may have negatively affected the level of vigor of music students. Since sportive activities and healthy diets are recommended to deal with stress, elective courses on physical activities and healthy nutrition should be offered to eliminate the low level of vigor (especially physical strength) of music students.

In this study, burnout, vigor and education satisfaction levels of music and art students in education faculty were compared and examined. It is thought that it would be beneficial to compare these students with other education faculty students and also with arts institutions outside the faculty of education. In addition, it is considered useful to carry out such studies internationally.

\section{REFERENCES}

[1] M. Kaspersen and K. Gotestam, "A survey of music performance anxiety among Norwegian music students," Eur. J. Psychiat, vol. 16, no. 2, pp. 69-80, 2002.

[2] A. Williamon and S. Thompson, "Awareness and incidence of health problems among conservatoire students," Psychol. Music, vol. 34, no. 4, pp. 411-430, Oct. 2006.

[3] M. Zander, E. Voltmer, and C. Spahn, "Health promotion and prevention in higher music education," Med. Probl. Perform Art, vol. 25, no. 2, pp. 54-65, 2010.

[4] H. Hildebrandt, M. Nubling, and C. V, "Increment of fatigue, depression and stage fright during the first year of high-level education in music students," Med. Probl Perform Art, vol. 27, no. 1, pp. 43-48, 2012.

[5] B. Wristen and S. Fountain, "Relationships between depression, anxiety, and pain in a group of university music students," Med. Probl. Perform. Art, vol. 28, no. 3, pp. 152-158, 2013.

[6] C. R. Panebianco-Warrens, L. Fletcher, and G. Kreutz, "Health-promoting behaviors in South African music students: A replication study," Psychol. Music, vol. 43, no. 6, pp. 779-792, Nov. 2015.

[7] A. van Goethem and J. Sloboda, "The functions of music for affect regulation," Music. Sci., vol. 15, no. 2, pp. 208-228, Jul. 2011.

[8] J. DeMarco, J. L. Alexander, G. Nehrenz, and L. Gallagher, "The Benefit of Music for the Reduction of Stress and Anxiety in Patients Undergoing Elective Cosmetic Surgery," Music Med., vol. 4, no. 1, pp. 44-48, Jan. 2012.

[9] S. Sergeant and M. Mongrain, "Are positive psychology exercises helpful for people with depressive personality styles?” J. Posit. Psychol., vol. 6, no. 4, pp. 260-272, Jul. 2011.

[10] E.-Y. Hwang and S.-H. Oh, "A Comparison of the Effects of Music Therapy Interventions on Depression, Anxiety, Anger, and Stress on Alcohol-Dependent Clients: A Pilot Study," Music Med., vol. 5, no. 3, pp. 136-144, Jul. 2013.

[11] J. Koenig et al., "I Need to Hear Some Sounds That Recognize the Pain in Me: An Integrative Review of a Decade of Research in the Development of Active Music Therapy Outpatient Treatment in Patients With Recurrent or Chronic Pain," Music Med., vol. 5, no. 3, pp. 150-161, Jul. 2013. 
[12] B. A. Bailey and J. W. Davidson, "Amateur group singing as a therapeutic instrument," Nord. J. Music Ther., vol. 12, no. 1, pp. 18-32, 2003.

[13] P. J. Jutras, "The benefits of adult piano study as self-reported by selected adult piano students," J. Res. Music Educ., vol. 54, no. 2, pp. 97-110, 2006.

[14] J. Ginsborg, C. Spahn, and A. Williamon, Health promotion in higher music education, in Music, Health, and Wellbeing, Oxford University Press, pp. 356-366, 2012.

[15] H. Gembris, R. A. R. MacDonald, G. Kreutz, and L. Mitchell, Music-making as a lifelong development and resource for health, in Music, health and well-being, Eds. Oxford: Oxford University Press, pp. 367-382, 2012.

[16] H. C. Schonberg, Horowitz, Vladimir, Grove Music Online. Oxford Music Online, 2010.

[17] J. J. Hakanen and W. B. Schaufeli, "Do burnout and work engagement predict depressive symptoms and life satisfaction? A three-wave seven-year prospective study," J. Affect. Disord., vol. 141, no. 2-3, pp. 415-424, 2012.

[18] K. Narainsamy and S. Van Der Westhuizen, "Work Related Well-Being: Burnout, Work Engagement, Occupational Stress and Job Satisfaction Within a Medical Laboratory Setting," J. Psychol. Africa, vol. 23, no. 3, pp. 467-474, Jan. 2013

[19] D. G. Moore, K. Burland, and J. W. Davidson, "The social context of musical success: A developmental account," Br. J. Psychol., vol. 94, no. 4, pp. 529-549, Nov. 2003.

[20] E. Diener, "Subjective well-being: The science of happiness and a proposal for a national index.," Am. Psychol., vol. 55, no. 1, pp. 34-43, 2000.

[21] E. L. Deci and R. M. Ryan, "Self-determination theory: A macrotheory of human motivation, development, and health.," Can. Psychol. Can., vol. 49, no. 3, pp. 182-185, 2008.

[22] S. Kilic, T. Tanrikulu, and H. Ugur, "Job satisfaction and social comparison levels of teachers working for state schools," Int. J. Hum. Sci., vol. 10, no. 1, pp. 760-779, 2013.

[23] S. Evans et al., "Mental health, burnout and job satisfaction among mental health social workers in England and Wales," Br. J. Psychiatry, vol. 188, no. 1, pp. 75-80, 2006.

[24] M. Gursel, A. M. Sunbul, and H. Sari, "An analysis of burnout and job satisfaction between Turkish headteachers and teachers," Eur. J. Psychol. Educ., vol. 17, no. 1, pp. 35-45, Mar. 2002.

[25] A. Koustelios and N. Tsigilis, "The relationship between burnout and job satisfaction among physical education teachers: a multivariate approach," Eur. Phys. Educ. Rev., vol. 11, no. 2, pp. 189-203, Jun. 2005.

[26] J. Ogresta, S. Rusac, and L. Zorec, "Relation between burnout syndrome and job satisfaction among mental health workers.," Croat. Med. J., vol. 49, no. 3, pp. 364-74, Jun. 2008.

[27] A. Ozyurt, O. Hayran, and H. Sur, "Predictors of burnout and job satisfaction among Turkish physicians.," QJM, vol. 99, no. 3, pp. 161-169, Mar. 2006.

[28] Z. Filiz, "An analysis of the levels of job satisfaction and burnout of teachers," J. Manag. Econ. Bus., vol. 10, no. 23 , pp. $157-172,2014$.

[29] H. J. Freudenberger, "Staff Burn-Out," J. Soc. Issues, vol. 30, no. 1, pp. 159-165, Jan. 1974.

[30] C. Maslach, S. E. Jackson, and M. P. Leiter, Maslach burnout inventory manual, 3rd ed. CA: Consulting Psychologists Press, 1996.

[31] W. B. Schaufeli and D. Enzmann, "The burnout companion to study and practice: A critical analysis," 1998.

[32] L. Karabiyik, M. Eker, and A. Anbar, "Determining the factors that affect burnout among academicians," Ankara Univ. J. Soc. Sci., vol. 63, no. 2, pp. 91-115, 2008.

[33] C. Maslach, W. B. Schaufeli, and M. P. Leiter, "Job Burnout," Annu. Rev. Psychol., vol. 52, no. 1, pp. 397-422, Feb. 2001

[34] N. Bayram, S. Gursakal, and N. Bilgel, "Burnout, vigor and job satisfaction among academic staff," Eur. J. Soc. Sci., vol. 17, no. 1, pp. 41-53, 2010.

[35] R. E. Demirbatır and D. Engür, "Academicians' Burnout, Vigor and Occupational Satisfactions in the Department of Fine Arts Education: A Sample of Uludag University," Journal of Education and Training Studies, vol. 6, no. 7. pp. 86-93, 2018.

[36] N. Bilgel, N. Bayram, H. Ozdemir, F. Dogan, and D. Ekin, "Work engagement, burnout and vigor among a group of medical residents in Turkey," Br. J. Educ. Soc. Behav. Sci., vol. 2, no. 3, pp. 220-238, 2012.

[37] A. Shirom and S. Melamed, "Shirom-Melamed burnout and vigor measures," 2005.

[38] R. E. Demirbatir, "Relationships between psychological well-being, happiness, and educational satisfaction in a group of university music students," Educ. Res. Rev., vol. 10, no. 15, pp. 2198-2206, 2015.

[39] C. Spahn, S. Strukely, and A. Lehmann, "Health conditions, attitudes toward study and attitudes toward health at the beginning of university study: Music students in comparison with other student populations," Med. Probl. Perform. Art., vol. 19, no. 1, pp. 26-33, 2004.

[40] A. M, K. T, S. YY, E. S, E. H, and A. M., "Anxiety, depression and stressful life events among medical students: a prospective study in Antalya, Turkey," Med Edu, vol. 35, pp. 12-17, 2001.

[41] B. M et al., "Depressive symptomatology among university students in Denizli, Turkey: prevalence and sociodemographic correlates," Croat Med J, vol. 46, no. 1, pp. 96-100, 2005.

[42] N. Bayram Arlı, M. Aydemir, and E. Çelik, "Çalışan Kıskançlığı, İş Tatmini, Tükenmişlik ve Dinçlik Arasındaki İlişkiler: Beyaz Yaka Çalışanlar Üzerine Bir Araştırma," J. Econ. Cult. Soc., vol. 59, no. 1, pp. 31-43, 2019. 